\title{
FORMAÇÃO EM JORNALISMO NA PERSPECTIVA DO DOCENTE: UM ES- TUDO NO INTERIOR DO MARANHÃO
}

\author{
THAISA BUENO \\ UNIVERSIDADE FEDERAL DO MARANHÃO \\ SÃO LUÍS, MARANHÃO, BRASIL \\ THAISABU@GMAIL.COM \\ MARCO ANTONIO GEHLEN \\ UNIVERSIDADE FEDERAL DO MARANHÃO \\ SÃO LUÍS, MARANHÃO, BRASIL \\ GEHLEN.M@GMAIL.COM
}

HTTP://DX.DOI.ORG/10.5902/2316882X26982 
FORMAÇÃO EM JORNALISMO NA PERSPECTIVA DO DOCENTE: UM ESTUDO NO INTERIOR DO MARANHÃO

Resumo: Este artigo discute a formação em Jornalismo a partir da realidade da Universidade Federal do Maranhão. O estudo verifica como os docentes enxergam os avanços e as perdas da formação com o desmembramento da Comunicação Social em cursos específicos. O levantamento qualitativo inclui entrevista as 25 professores que integram/integraram o curso na instituição que, em 2016, completou dez anos.

Palavras-chave: Formação em Jornalismo; Novas Diretrizes; Imperatriz (MA).

FORMACIÓN PERIODISMO EN PERSPECTIVA DE LA ENSEÑANZA: UN ESTUDIO EN EL ESTADO DE MARANHÃO

Resumen: En este trabajo se analiza la formación en periodismo de la realidad de la Universidad Federal de Maranhão. El estudio verifica como maestros ven el progreso y la pérdida de la formación con la ruptura de la comunicación social en los cursos específicos. La encuesta cualitativa incluye entrevistar a los 25 profesores que integran / curso integrado en la institución, en 2016, completó diez años.

Palabras clave: La formación de periodistas; Nuevas directrices; Imperatriz (MA).

TRAINING IN JOURNALISM FROM THE TEACHER'S PERSPECTIVE: A STUDY IN THE INTERIOR OF MARANHÃO

Abstract: Abstract: This article discusses training in Journalism from the reality of the Federal University of Maranhão. The study examines how teachers see the progress and losses of training through the breakdown of Social Communication into specific courses. The qualitative survey includes interview the 25 teachers that integrate / integrated the course in the institution that, in 2016, completed ten years.

Keywords: Training in Journalism; New Guidelines; Imperatriz (MA). 


\section{INTRODUÇÃO}

O que é primordial para a formação de um Jornalista? Teóricos, profissionais, aspirantes à uma vaga nas universidades, consumidores de conteúdo midiático, enfim, diferentes setores envolvidos direta ou indiretamente nessa seara têm uma opinião sobre o que esperam de um jornalista e, portanto, são guias do que se poderia implicar a formação desse profissional. De acordo com o Mapeamento dos programas de treinamento nas empresas de comunicação em 2012, do programa Itaú Cultural, que abordou, entre outras questões, quais características o jovem jornalista deveria ter, verificou-se que de um total de 123 respostas dos veículos consultados, 41 indicavam conhecimento como o quesito mais importante e, destes, 15 apontaram a gramática e a redação como prioridades: "domínio da gramática e redação perfeita foram apontados pelos veículos como as principais características no processo de seleção do novo jornalista" (ITAÚ CULTURAL, 2012, p. 23). Além disso, os veículos assinalaram também preocupação quanto à formação cultural e humanística. Por outro lado, domínio técnico, citado como faro jornalístico e conhecimento de ferramentas de comunicação, só apareceu em nove das 123 respostas. Isso representa menos de $8 \%$ do total e mostra que o mercado está muito mais flexível para habilidades especificas da profissão e muito mais interessado num profissional que tenha amplo domínio do seu idioma, escrita coesa e embasamento cultural.

Diante do exposto até aqui, parece pertinente concordar com Lopes (2013) que, ao explicar a diferença entre identidade e papel do jornalista, argumenta que a primeira está relacionada ao significado, enquanto o segundo diz respeito à função. Assim, a identidade jornalística não tem a ver somente com a prática, mas também com valores, crenças, saberes, história, relações de poder, entre outros elementos que ligam os indivíduos pertencentes a um grupo. Por fim, equilibrar esses dois eixos aparenta ser o desafio do jornalista neste século, seja para quem já está no mercado, seja para os novos jornalistas recém-egressos da universidade.

O tema por si só já suscita discussões, some-se a isso o fato de que em 2015 expirou o prazo divulgado pelo Governo Federal para que os cursos de Comunicação Social em todo o país reformulassem suas grades e adotassem currículos distintos para suas habilitações (Publicidade e Propaganda, as Relações Públicas e Rádio \&TV), despedindo-se, definitivamente, da 
base comunicacional a qual foram atrelados até então. $O$ assunto ainda é bastante polêmico entre os profissionais da área e divide opiniões dos docentes que compõem os colegiados responsáveis pela reconfiguração das grades nas universidades pelo país. Particularmente entre as instituições que se encontram atrasadas na instauração dos novos projetos, como é o caso do Curso de Comunicação Social- Habilitação em Jornalismo, da Universidade Federal do Maranhão, centro de Imperatriz, que ainda em 2017 está em fase de finalização do seu novo Plano Político Pedagógico.

Deste modo, a proposta deste artigo é, a partir de uma pesquisa qualitativa junto ao corpo docente do curso de Jornalismo na UFMA de Imperatriz, a segunda maior cidade do Estado e há 600 quilômetro da capital, debater sobre a formação dos futuros profissionais de Jornalismo no país, a realidade da formação numa cidade do interior, resultado direto das políticas de interiorização do ensino superior, bem como sobre as mudanças propostas pela Novas Diretrizes CurricularesNacionaistendo como foco o olhar desses docentes.Embora a investigação seja focada numa realidade bem peculiar: uma cidade do interior do Estado mais pobre do país (CENSO, 2016), o debate pode ser estendido e contribuir para pensar a formação em outros pontos do Brasil, uma vez que trata diretamente do olhar do professor (formador) sobre o futuro de uma profissão tão em voga nas discussões sobre ética e postura na atualidade.

O curso de Jornalismo na instituição pesquisada completou dez anos em 2016. Acatando a determinação do Ministério da Educação para os cursos em todo o território nacional, vai passar pela primeira mudança curricular desde a sua formação no segundo semestre de 2017, ou seja, um ano e meio depois do prazo determinado. A instituição já formou 176 estudantes e em dez anos o quadro inicial de professores efetivos cresceu de 8 para 21. Em 2016, o curso possuía dois mestres, dez doutores, oito doutorandos com previsão de conclusão até dezembro de 2017 e dois pós-doutores. Outra peculiaridade do curso é que o seu quadro é formado por professores representantes de todas as regiões do País. No corpo docente atual são profissionais naturais das regiões Nordeste (9), Sul (4), Centro-Oeste (5), Sudeste (2) e Norte (1). Do Maranhão há três professores das cidades de São Luís e de Bacabal. É interessante observar que não há nenhum professor natural da cidade de Imperatriz, embora alguns ex-alunos da instituição já tenham atuado como educadores substitutos ali. O recorte de estudo incluiu a aplicação de questionários e a condução de

Rev.Cad.Comun. Santa Maria, v.21, n.3, art 4, p. 68 de 81, set/dez.2017 
entrevistas dirigidas aos 34 professores que atuam ou atuaram em algum momento da instituição nesses dez anos. 25 responderam, incluindo 20 professores do quadro efetivo atual.

\section{A FORMAÇÃO: UMA CONTENDA HISTÓRICA}

Para entender o surgimento e desenvolvimento do ensino de Jornalismo em nosso país e até poder olhar de maneira crítica para a realidade no Maranhão e, particularmente, em Imperatriz, se faz pertinente conhecer o processo de formatação desse campo do conhecimento. Para além das discussões epistemológicas, Melo (2004) e Traquina (2005) defendem que para compreender a formação nesta área de conhecimento é preciso fazer um resgate histórico da institucionalização do Jornalismo enquanto campo universitário. De acordo com Melo (2004), embora os Estados Unidos sejam pioneiros no ensino de Jornalismo, há precedentes no continente europeu, especificamente na Alemanha, na França e na Suíça, todos no fim do século $X X$.

Melo (2004) aponta que a principal diferença entre o modelo europeu e o americano diz respeito ao âmbito educativo. O curso europeu tinha perfil "academicista" e pretendia "alavancar uma 'ciência da imprensa", (MELO, 2004, p. 75), enquanto o norte-americano era mais "modesto", pois pretendia simplesmente aperfeiçoar tipógrafos, ou seja, "ampliar seu conhecimento no âmbito das artes e das ciências" (idem). Mas paralelamente a esses debates, Traquina (2005) pontua que sempre foi forte, também, os grupos (profissionais e até pesquisadores) que defendiamqueas escolas de Jornalismo não eram necessárias para uma formação na área.

Vale ponderar que essa ideia de que o Jornalismo se aprende apenas na prática permanece ainda hoje em alguns nichos da sociedade, inclusive na perspectiva de alguns editores do mercado jornalístico nacional. Mino Carta, editor da revista Carta Capital, escreveu em 2001, após a decisão da $16^{\circ}$ Vara Federal de São Paulo de extinguir a obrigatoriedade do diploma de jornalista para exercício da profissão, que "jornalismo não é ciência, na melhor das hipóteses pode ser arte". Além disso, ele defendeu no texto que "a melhor escola é o próprio jornal".

Em 2012, também sobre a discussão da importância do diploma, na coluna para a revista Brasileiros, Ricardo Kotscho rebateu as críticas do então ombudsman da Folha de S.PauloCarlos Eduardo Lins da Silva e se po- 
sicionou em coluna daquele jornal dizendo que "o diploma, sempre achei que é uma falsa questão. [...] Não há necessidade de uma formação de quatro anos em escola superior para alguém ser jornalista, é totalmente irrelevante" (KOTSCHO, 2009, página da web).

Mas apesar de ainda hoje encontrarmos resquícios dessa posição ideológica, é notório ponderar que o contrário, ou seja, a defesa da formação em Jornalismo na universidade é bem antiga também e tem, até mesmo, reverberado no mercado. Joseph Pulitzer, diretor da cadeia jornalística liderada pelo New York World e personalidade que dá nome ao maior prêmio da área nos Estados Unidos, posicionou-se a favor do ensino de Jornalismo ainda no século passado. "Ninguém numa redação tem tempo ou vocação para ensinar a um repórter cru as coisas que deveria saber antes de realizar o mais simples trabalho jornalístico" (PULITZER, 2009 apud LUZ, 2010, p. 260).

Obviamente que quem conhece um pouco da história desse jornalista sabe que durante sua carreira tornou-se evidente o trato sensacionalista que era outorgado ao seu jornal. Mas ainda assim, ele entendia que a formação era um modo de elevar a qualidade do material publicado. Conforme Vasconcelos (2012, p.2) o editor chegou a conceder "US\$ 1 milhão de dólares à Universidade de Colúmbia para a criação de uma Escola de Jornalismo". Segundo Melo (2004), a polêmica norte-americana em torno da validação da formação universitária de jornalistas "tem como pano de fundo o sentimento de desconforto da sociedade civil no tocante à exacerbação do sensacionalismo da imprensa" (2004, p.77). O autor julga que as empresas lideradas por Pulitzer cultivavam o sensacionalismo e por isso ele defendeu e investiu no ensino universitário como uma forma de absolvição:

Redimindo-se, em certo sentido, das responsabilidades pelo cultivo do sensacionalismo até então compartilhado por suas empresas, Joseph Pulitzer lidera a ala dos donos de jornais que se comprometem com a melhor qualificação dos profissionais da notícia, dando-Ihes embasamento humanístico. Ele ofereceu uma doação de dois milhões de dólares para a universidade que se comprometesse a educar adequadamente os jovens jornalistas (MELO, 2004, P. 77).

Seja por isso, ou por outros motivos, o fato é que ele foi uma voz importante na luta por uma formação para os jornalistas nos Estados Uni-

Rev.Cad.Comun. Santa Maria, v.21, n.3, art 4, p. 70 de 81, set/dez.2017 
dos. Inclusive, conforme explica Melo (2004), a doação dessa quantia seria destinada a Universidade de Havard, no entanto, o Reitor Eliot propôs um currículo que "privilegiava os assuntos 'técnicos' em detrimento dos “intelectuais”' (p. 77). Em razão disso, Pulitzer escreveu um ensaio para a revista North American Review, que mais tarde viria a ser publicada em um livro titulado no Brasil "A escola de jornalismo: a opinião pública” (The CollegeofJournalism, no original), defendendo que o ensino de Jornalismo não devia ser comercial. Em seus argumentos, Pulitzer confronta o ensino e afirma que o âmbito universitário deve trabalhar para a comunidade e não para o comércio. Em suas palavras, a Escola de Jornalismo "deve exaltar os princípios, o conhecimento e a cultura, [...] deve construir ideias" (MELO, 2004, p.77).

\section{O ENSINO DE JORNALISMO NO BRASIL}

De acordo com as Diretrizes Curriculares Nacionais para o Curso de Jornalismo do MEC 2013, a demanda da educação dos jornalistas "floresceu no caldo de cultura gerado pela industrialização da imprensa" (p. 7). O texto aponta que nesse período os jornais se transformaram em empresas autossustentáveis, desvinculando-se dos partidos políticos e dessa forma, surgiu a necessidade de profissionais que produzissem notícias de interesse público. A ponderação corrobora o pensamento de Melo (2010), para quem:

A profissão de Jornalista começa a adquirir identidade social no Brasil na passagem do século XIX para o século XX, quando as organizações que editam jornais e revistas se convertem em empresas comerciais, financiadas pela publicidade, necessitando, portanto de agentes produtivos que optam pela atividade noticiosa como fonte de realização intelectual e de subsistência econômica. (MELO, 2010, p. 80)

Melo (2000) esclarece que, enquanto o Jornalismo caminhava para a industrialização, os profissionais que atuavam na profissão, contraditoriamente, não eram instruídos especificamente para o exercício e, no entanto, eram oriundos das Faculdades de Direito, que na época eram onde se formavam aqueles que buscavam ser influentes na sociedade. Entretanto, ainda conforme o autor (2000), a formação em Direito mostrou-se insatisfatória para atender às necessidades das empresas jornalísticas, pois

Rev.Cad.Comun. Santa Maria, v.21, n.3, art 4, p. 71 de 81, set/dez.2017 
o texto desses profissionais das leis era complicado, exageradamente requintado, como se destinado apenas aos instruídos.

Assim, quando foi fundada em 1908, por Gustavo de Lacerda, a Associação Brasileira de Imprensa $(A B I)$ possuía como uma de suas pautas a defesa pela formação específica em Jornalismo. A partir daí, 10 anos depois, João Guedes de Melo, então presidente da $A B I$, propôs ao Primeiro Congresso Brasileiro de Jornalistas realizado em 1918, a criação de uma Escola de Jornalismo seguindo o modelo do ensino norte-americano. No entanto, Melo (2004) justifica que se tratava de uma "proposta arrojada para a época. Por isso mesmo permaneceu inalcançada até o final da primeira metade do século XX" (2000, p. 82) e o projeto foi engavetado.

Contudo, a partir da década de 20 do século passado, houve "grande movimentação por parte dos intelectuais da educação no Brasil para a implantação de uma universidade que atendesse as demandas liberais" (DINIZ, 2010, p. 5). Assim, em 1935 foi criada a Universidade do Distrito Federal (UDF), pelo educador Anísio Teixeira, no Rio de Janeiro, então capital do país. Três anos mais tarde essa universidade receberia o primeiro curso de Jornalismo do país. No entanto, em pouco tempo a universidade foi fechada pelo então Ministro da Educação, Gustavo Capanema, que a considerava inconstitucional.

\footnotetext{
O encerramento do curso certamente chegou ao fim com o fechamento da Universidade do Distrito Federal, quando o Ministro Gustavo Capanema criou a Universidade do Brasil e decretou que todos os cursos, alunos e professores fossem a partir de então, transferidos e submetidos às regras da nova instituição. Era o fim do sonho de uma universidade concebida com a proposta de estimular o acesso ao conhecimento e à pesquisa científica, ainda que essas sejam metas que nunca permaneceram arraigadas na cultura brasileira, em razão da proposta de implantação da universidade no país. (DINIZ, 2010, p. 11).
}

Após essa breve experiência, seria fundada em 1943 a Faculdade de Jornalismo Cásper Líbero, em São Paulo, exatos cinco anos após o fechamento da UDF. Hime (2004) explica que, apesar da faculdade ter surgido em 1943, o curso só entrou em funcionamento quatro anos depois, devido aos entraves legislativos.

$\mathrm{Na}$ atualidade, de acordo com levantamento publicado pela Folha de S.Paulo em 2016 - "Ranking Universitário da Folha" - no Brasil, 315 institui- 
ções oferecem o curso de Comunicação Social-Habilitação em Jornalismo no Brasil. Dessas, 275 são particulares e 40 são públicas. No Maranhão são três instituições autorizadas: a UFMA (São Luís e Imperatriz), a Faculdade de Ciências Humanas e Sociais Aplicadas (FAC São Luís) e o Instituto Maranhense de Ensino e Cultura (Imec). No Maranhão, além de São Luís, que é a Capital e oferece a habilitação tanto nas universidades públicas quanto nas faculdades privadas, apenas o município de Imperatriz oferta o curso, na UFMA. Pelo ranking que cataloga os melhores e os piores cursos do país, o curso da UFMA ocupa a $52^{\mathrm{a}}$ posição. Apesar da colocação longínqua, está bastante a frente das concorrentes particulares, ranqueadas em 176 e 294, respectivamente.

\section{O CURSO DE JORNALISMO DE IMPERATRIZ, AS NOVAS DIRETRI- ZES E A FORMAÇÃO}

Por acreditar que o perfil dos professores tem relação direta e indireta com o contorno dos estudantes por eles guiados durante a formação, esta pesquisa buscou entrevistar os docentes que atuaram no curso desde sua implementação até os dias de hoje. A proposta é discutir o tema formação e também entender como esses profissionais, que atuam diretamente com os novos jornalistas, pensam sobre o perfil profissional e as mudanças na nova grade. As entrevistas foram realizadas entre o período de 03 de agosto e 04 de outubro de 2016 a fim de conhecer o universo dos educadores, bem como suas opiniões sobre assuntos pertinentes ao curso e à profissão de jornalista.

Dos 34 professores que atuam/atuaram no curso em dez anos, 25 responderam ao questionário. Dos professores que entraram no primeiro ano do curso, quatro permanecem. Atualmente o quadro é composto por 21 professores e desses, apenas dois não responderam ao questionário. Dos 25 respondentes, 17 são doutores, 8 são mestres e um possui pós-doutorado.No corpo docente atual, são profissionais naturais de todas as regiões do país. Essa particularidade é uma característica importante para entender a formação do curso em Imperatriz, porque mostra como é diversificado o olhar desses profissionais sobre a área, já que são advindos de todos as regiões do país e trazem experiências distintas. Além disso tanta pluralidade permite enxergar posicionamentos que representam em parte olhares menos regionais, o que permite ampliar a discussão para

Rev.Cad.Comun. Santa Maria, v.21, n.3, art 4, p. 73 de 81, set/dez.2017 
além do recorte da pesquisa.

Quanto à formação, observou-se que dos 21 docentes efetivos atualmente, 16 possuem formação em Jornalismo, dois em Publicidade e Propaganda, dois em Ciências Sociais e um em Filosofia. Isso mostra que a maioria é jornalista, mas que a área de humanas é significativa também.

Quanto à sindicalização, verificou-se que poucos docentes consultados são sindicalizados. No entanto, alguns são filiados ao Sindicado Nacional dos Docentes das Instituições de Ensino Superior (Andes) e à Federação de Sindicatos de Professores e Professoras de Instituição Federais de Ensino Superior e de Ensino Básico Técnico e Tecnológico (Proifes). Um docente escolheu a opção "Outros" e informou que se trata do Sindicato dos Jornalistas do Município do Rio de Janeiro.

Foi perguntado também quais motivações impulsionaram os docentes a seguir a carreira em sala de aula. A maioria dos pesquisados informou que foi por vocação, enquanto outros disseram que queriam pesquisar. Os que escolheram a opção "Outros" deram respostas como: queria formar jornalistas éticos, por ter maior destaque, pela docência dar mais oportunidade de crescimento pessoal e intelectual. Alguns responderam que o salário era mais atrativo que o mercado e um professor respondeu que estava cansado do mercado. Um ponto positivo é que quase metade dos consultados estão atuando como docentes por vocação, o que pode representar satisfação com a atividade realizada e, consequentemente, boa atuação com professor.

A maior parte dos professores consultados com formação em Jornalismo já atuaram no mercado como profissionais da área. Quanto à atuação como profissional jornalista, foi verificado que as editorias mais mencionadas foram: Geral, Política, Economia e Cultura. Os que escolheram a opção "Outros", informaram as editorias: Rural, Tecnologia, Jornalismo popular e Meio ambiente. Isso pode representar um conhecimento mais aprofundado dos docentes, pelo fato de já terem atuado como jornalistas, e, ainda, representar uma complementação para à formação do aluno, já que há um diálogo real com a experiência desses professores em várias áreas e temáticas.

Quantos aos cargos já ocupados pelos docentes com formação em Jornalismo, o cargo de Assessoria de Comunicação foi o mais mencionado entre os pesquisados. Outros cargos também citados são editor de impresso, repórter de impresso, editor de site ou portal, repórter de rádio e

Rev.Cad.Comun. Santa Maria, v.21, n.3, art 4, p. 74 de 81, set/dez.2017 
repórter de TV. Os cargos de repórter de online, medidor de redes sociais e editor de TV também foram listados. O fato de muito terem experiência em assessoria é um ponto muito positivo, já que é o mercado que mais emprega os formados na cidade. De acordo com uma pesquisa do qual esse trabalho faz parte, foi constatado que, dos formados consultados que atuam na área de formação, 48,8\% é na área de Assessoria de Comunicação.

Acerca da obrigatoriedade de formação superior para exercício da atividade jornalística, 18 dos professores consultados informaram que são a favor enquanto 5 disseram ser contra e 2 responderam que depende. Como já mencionado anteriormente, essa questão é, de fato, polêmica.

Foi perguntado quais características os professores acreditam que um bom jornalista deve ter. Qualidades como bom texto, pro-atividade, ética, curiosidade, criticidade e criatividade foram mais comuns. Além disso, observa-se que os docentes consideram a visão crítica, a curiosidade e um bom texto como requisitos básicos para um bom jornalista.

Aos docentes foi perguntado também uma qualidade do curso da universidade em questão. Foi possível observar que, de acordo com a visão dos docentes consultados, as qualidades do curso de Jornalismo desta instituição estão relacionadas à capacitação do corpo docente, bem como sua integração com os alunos, além da interação com as questões da relacionadas à cidade. Chama atenção o fato de nenhum ter destacado pontos referentes à infraestrutura, ou seja, um ponto a ser melhorado; e não terem mencionado a qualidade dos discentes.

Por outro lado, foi perguntado aos docentes qual era a maior deficiência do acadêmico de Jornalismo desta universidade. As respostas mais comuns foram relacionadas à formação básica: problemas com escrita, falta de leitura e dificuldades com interpretação de texto. Mas falta de entusiasmo e preguiça também apareceram nas respostas. As observações dos docentes mostram que as deficiências dos alunos de Jornalismo desta instituição são justamente as características básicas que um bom jornalista deve ter de acordo com o Mapeamento dos programas de treinamento nas empresas de comunicação em 2012, realizado pelo Itaú Cultural, que apontou habilidades e competências como bom texto, leitura, bagagem cultural como essenciais para um bom jornalista. Dessa forma, é preciso pensar numa forma de desenvolver o interesse pela leitura.

Foi consultada também a opinião do docente em relação à recente 
CADERNOS DE COMUNICAÇÃO

UNIVERSIDADE FEDERAL DE SANTA MARIA

mudança do curso, que deixou de ser uma habilitação de Comunicação Social e passou a ser especificamente de Jornalismo. Dos consultados, 12 responderam que concordaram com a mudança, enquanto dez discordaram. Dois docentes responderam que essa questão é irrelevante e um informou que ainda não participou da transição e, portanto, teria opinião formada.

Destacam-se algumas respostas:

Sim. Por permitir uma abordagem mais direcionada na área e um contato mais cedo com as teorias e práticas do Jornalismo (DOCENTE 5).

Sim. Pode torná-lo mais eficaz e focal (DOCENTE 7).

Sim. A mudança tende a comtemplar e fortalecer as especificidades da área (DOCENTE 9).

Sim, embora continue reconhecendo a necessidade de vincular jornalismo com as teorias da comunicação. Focar em Jornalismo traz ganhos e profundidade aos enfoques acadêmicos-profissionais (DOCENTE 10).

Apoio totalmente. Jornalismo é uma área ampla e precisa de um curso específico (DOCENTE 11).

Sim, nossa especificidade precisa ser respeitada. Não existe a profissão de comunicador social (DOCENTE 12).

Sim. Quanto mais especifico mais chances de formação completa e menos genérica (DOCENTE 15)

Sim. A mudança fortalece a área da comunicação, porque incentiva o estudante a estuda-la mais profundamente. Irá conhecer detalhadamente a produção cientifica e atuação profissional de uma das profissões mais importantes da comunicação: o jornalismo. A proposta é articular os conhecimentos específicos, os saberes interdisciplinares e a atuação crítica frente aos desafios que vai enfrentar como profissional. Nos currículos anteriores, a formação era desarticulada. Havia uma parte com disciplinas genéricas de comunicação, onde eram ministrados conteúdos teóricos sem articulação com a segunda parte do curso, composta por disciplinas teórico-práticas do Jornalismo. O Jornalismo era visto como algo menor, 'uma forma de escrever', visão rasa que ignorava o avanço científico da produção jornalística e a importância social da profissão. E fazer o 'curso de Comunicação Social' ainda passava a falsa impressão de que o estudante sairia de lá 'formado' em diversas profissões (jornalista, publicitário, radialista, cineasta), só porque estudo os conteúdos genéricos

Rev.Cad.Comun. Santa Maria, v.21, n.3, art 4, p. 76 de 81, set/dez.2017 
da comunicação, um grande engano, porque não se aprofundava em nada disso. Hoje os cursos específicos objetivam incentivar maior conhecimento da área, fazendo o estudante se aprofundar na área específica, dominar os conhecimentos teóricos para melhorar sua ação profissional e reafirmar seu compromisso com a sociedade [...] (DOCENTE 17).

Sim. Porque possibilita aprofundar as questões que são concernentes, exclusivamente ao campo (DOCENTE 26).

Não. Acredito que a comunicação é um campo mais amplo e abrangente" (DOCENTE 2).

Não. Achava positiva a formação básica como comunicadores compartilhada com as outras habilitações. Acho que as áreas estão cada vez mais convergentes, e isso pode promover uma divergência ainda na universidade (DOCENTE 3).

Não, pois limita a proposta de formação, que está sempre em transformação (DOCENTE 4).

Não, porque perde-se a interdisciplinaridade (DOCENTE 6).

Não. Creio que a Comunicação Social traz para o profissional uma visão mais ampla, essencial para a formação de um bom jornalista. Muito além das técnicas, é preciso entender a lógica das coisas, a constituição da sociedade, sua organização. Não vejo a comunicação se não como um campo interdisciplinar (DOCENTE 20).

Não concordo! Na sociedade contemporânea o conceito de comunicação social é fundamental (DOCENTE 25).

Percebe-se que essa é uma questão que divide opiniões dos docentes, pois trata-se, de fato, de uma questão polêmica. O ponto positivo é que poucos se mostraram indiferentes quanto ao debate, pois, a partir da observação dos primeiros capítulos, constatou-se que esta é uma querela ampla e complexa. Se mostrar indiferente é estar alheio às questões que concernem o curso. Além disso é enriquecedor para o aluno ter contato com professores que têm opiniões distintas, já que isso instiga a criticidade.

\section{CONCLUSÃO}

Em meio ao atraso da implementação das novas diretrizes e dacelebração de dez anos do curso da UFMA de Imperatriz, essa pesquisa se propôs a investigar o universo da formação em Jornalismo em Imperatriz,

Rev.Cad.Comun. Santa Maria, v.21, n.3, art 4, p. 77 de 81, set/dez.2017 
partindo da visão do corpo docente da instituição. A partir da análise das respostas colhidas, foi possível observar que o quadro de docentes, composto por 21 professores efetivos, dos quais 19 responderam ao questionário, possui alto grau de qualificação. Ainda mais, é oriundo de diversas regiões do país, possui experiência profissional na área de Jornalismo, a maioria não é sindicalizado e tem opiniões distintas, o que enriquece o debate dentro da academia.

Além disso, verificou-se também que, de acordo com o ponto de vista desses docentes em relação aos estudantes do curso da instituição em questão, ainda há muito a ser aperfeiçoado, como a leitura e a escrita, pois, conforme relataram, é defasada.

Já com relação às recentes mudanças ocorridas no cenário do Jornalismo, que são o ponto central deste trabalho, observou-se que não se trata de um assunto acabado, embora aprovadas e já praticadas em quase todas as instituições de ensino superior do país. Contudo, o tema ainda divide opiniões e acredita-se que o debate precisa continuar sendo instigado dentro da academia, uma vez que pressupõe-se que a formação de ensino superior deve ser sempre questionada e repensada.

$O$ resultado do estudo realizado numa universidade do interior do país pode ser particular, mas a revisão da literatura permite afirmar que as mudanças no ensino de Jornalismo, tal como a atuação profissional, não ocorreram de forma amena no decorrer da história. O ponto positivo é que a formação em Jornalismo está sendo trazida ao debate constantemente e isso permite repensar a forma de conceber o ensino e a profissão. E o lado negativo é que, segundo a visão dos docentes consultados em consonância com os teóricos pesquisados, há uma discrepância entre a teoria e a prática e que é perceptível o desafio da academia de buscar conciliar esses dois extremos.

Ademais, é importante afirmar que o presente estudo não pretende encerrar o assunto, contudo, tenciona servir como ponto de partida para futuras investigações. Ainda que seja revisto posteriormente, a presente análise se mostra relevante ao realizar constatações acerca da importância do professor no delineamento do perfil profissional dos novos profissionais jornalistas. Além disso, mostra que pontos de vista diferentes podem ser proveitosos para a formação acadêmica e a fomentação do debate dentro da academia. 


\section{REFERÊNCIAS}

DINIZ, Lidiane. Costa Rego e o Curso Pioneiro de Jornalismo da Universidade do Distrito Federal. Caxias do Sul, 2010. Disponível em: <http://www.intercom.org.br/papers/ nacionais/2010/resumos/R5-3085-1.pdf>. Acesso em: 9 jul. 2016

ENECOS. Campanha “Somos Todos Comunicação Social - Avalie sua Formação!". 2010. Disponível em: <https://docs.google.com/file/d/oBzwtX_QmPtcFYTYwNTAxMDYtZmE4ZSooYjY2LWI2MzYtY2VkODAyMmQ4NWM5/edit?hl=pt_BR>. Acesso em: 14 de ago. 2016.

FOLHA DE SÃO PAULO. Ranking universitário folha 2014, Jornalismo. Disponível em: <http://ruf.folha.uol.com.br/2014/rankingdecursos/jornalismo/>. Acesso em: 7 de ago. 2016.

IBGE - Instituto Brasileiro de Geografia e Estatística.IBGE divulga o rendimento domiciliar per capita 2016. <ftp://ftp.ibge.gov.br/Trabalho_e_Rendimento/Pesquisa_Nacional_por_Amostra_de_Domicilios_continua/Renda_domiciliar_per_capita/Renda_domiciliar_per_capita_2016.pdf>. Ačesso em: 01 de mai. 2017.

KOTSCHO, Ricardo. Ombudsman da Folha defende a autorregulação da imprensa, 2009. Disponível em: <http://brasileiros.com.br/2009/09/ombudsman-da-folha-defende-a-autorregulacao-da-imprensa/>. Acesso em: 27 de set. 2016.

LOPES, Fernanda Lima. Reflexões sobre políticas educacionais para o ensino de jornalismo no Brasil nos primeiros anos do regime militar. 2013. Disponível em: <http:// www.ojs.ufpi.br/index.php/rbhm/article/view/3839/2216>. Acesso em: 26 de set. 2016.

Mapeamento dos programas de treinamento nas empresas de comunicação em 2012: uma relação necessária: academia e mercado/organização Nísio Teixeira. - São Paulo: Itaú Cultural, 2012. Disponível em: <https://issuu.com/itaucultural/docs/mapeamento_ rjc>. Acesso em: 25 de set. 2016.

MARSHALL, Leandro. Jornalista e escritor, Leandro Marshall explica porque o Jornalismo está cada vez mais parecido com a Publicidade: entrevista. [S.I.], v. 2, n. 5, p. 530-543, dez. 2016. Revista Observatório. Entrevista concedida a Jessica Torres sob orientação de Thaísa Bueno. Disponível em: <https://sistemas2.uft.edu.br:8004/index. php/observatorio/article/view/2581>. Acesso em: 09 jan. 2017.

MELO, José Marques de. Os primórdios do ensino de jornalismo. Florianópolis, 2004. In: Estudos em Jornalismo e Mídia. Volume I, $\mathrm{n}^{\circ} 2-2^{\circ}$ Semestre de 2004. Disponível em: <http://revistas.univerciencia.org/index.php/estudos/article/viewFile/5962/5431>. Acesso em: 10 de ago. 2014. - Costa Rego, o primeiro catedrático de jornalismo do Brasil, In: Intercom - 
CADERNOS DE COMUNICAÇÃO

UNIVERSIDADE FEDERAL DE SANTA MARIA

Revista Brasileira de Ciências da Comunicação, vol. XXIII, n.1, janeiro a julho de 2000. Disponível em: <http://www.portcom.intercom.org.br/revistas/index.php/revistaintercom/article/viewFile/2007/1785>. Acesso em: 12 de jul de 2016.

PULITZER, Joseph. A escola de jornalismo: a opinião pública. Tradução de Jorge Meditsch e Eduardo Meditsch. Florianópolis: Insular, 2009 apud LUZ, Andréa Aparecida da. Para que servem os cursos de Jornalismo?, 2010. Disponível em: < file://C:/Users/ ok/Downloads/604-624-1-PB.pdf >. Acesso em: 28 de set. 2016.

TRAQUINA, Nelson. Teorias do Jornalismo, porque as notícias são como são. Florianópolis: Insular, 2. Ed, 2005.

VASCONCELOS, Túlio Souza de. Uma Escola de Jornalismo é Necessária?. Disponível em: <http://www.revistas.univerciencia.org/index.php/anagrama/article/viewFile/7910/7364>. Acesso em: 29 de set. 2016. 


\section{Thaisa Bueno}

Doutora em Comunicação pela Pontifícia Universidade Católica do Rio Grande do Sul (PUC-RS), mestre em Letras pela Universidade Federal do Mato Grosso do Sul. Jornalista. Coordena o grupo de pesquisa em Comunicação e Cibercultura (Gciber), na Universidade Federal do Maranhão; e integra o grupo de pesquisa em Ciberjornalismo, numa parceria com a UFMS. Atualmente é professora adjunta no curso de Jornalismo na UFMA em Imperatriz.

E-mail: thaisabu@gmail.com

\section{Marco Antonio Gehlen}

Doutor em Comunicação pela PUCRS (2016), mestre em \&quot;Agronegócios\&quot; (2009) pela Universidade Federal de Mato Grosso do Sul (UFMS); especialista em \&quot;Comunicação Empresarial\&quot; (2005) e graduado em \&quot;Comunicação Social - Jornalismo\&quot; (2002). É professor adjunto e pesquisador no curso de Jornalismo da Universidade Federal do Maranhão, campus de Imperatriz (MA).

E-mail: gehlen.m@gmail.com

RECEBIDO EM: 04/05/2017

ACEITO EM: 04/07/2017 